\title{
Psicología, niño y familia en la Argentina, 1900-1970. Perspectivas históricas y cruces disciplinares
}

\section{Psychology, child and family in Argentina, 1900-1970. Historical perspectives and disciplinary crossings \\ Psicologia, criança e família na Argentina, 1900-1970. Perspectivas históricas e cruzamentos disciplinares}

\section{Isabella Cosse*}

Consejo Nacional de Investigaciones Científicas y Técnicas - Universidad de Buenos Aires - UBA, Buenos Aires, Argentina.

Luciano N. García, Florencia A. Macchioli, \& Ana M. Talak (2014). Psicología, niño y familia en la Argentina, 1900-1970. Perspectivas históricas y cruces disciplinares, Buenos Aires, Biblos.

Psicología, niño y familia en la Argentina es una "rara avis". Es una obra colectiva pero no contiene un conjunto de ensayos reunidos de modo más o menos ocasional: emana de un equipo de trabajo unido por una trayectoria en común, una unidad de preocupaciones y de enfoques de trabajo. Como propondré en estas páginas, los autores han elegido bien utilizar la palabra "cruces" en el título porque esa noción constituye una clave nodal de su apuesta colectiva.

En primer lugar, el grupo y el enfoque de este libro involucran un programa de trabajo surgido en el marco de la consolidación de la historia intelectual en la línea abierta por Oscar Terán. En ese marco, el cruce entre psicología e historia se ha convertido en una tradición propia. Uno de cuyos impulsores, Hugo Vezzetti, está en el origen del libro, porque los autores forman parte de su equipo de trabajo. Sin embargo, la centralidad de su figura no opaca la voz propia de los autores que asume entidad por sí misma. En ese programa está en el centro la valorización de la especificidad de la teoría psicológica pero al mismo tiempo el esfuerzo por dotar de entidad explicativa al contexto histórico. Con esta inspiración, el libro ofrece una visión de largo aliento construida a partir del estudio de algunas de las figuras intelectuales más importantes y menos estudiadas para comprender la configuración del conocimiento experto sobre la familia y la infancia / adolescencia en el siglo XX. La idea fuerza que recorre el libro es 
casi un programa: pensar desde la psicología la historia intelectual. Nos llama la atención a los historiadores sobre la centralidad de lo psicológico en sí mismo y a los psicólogos que el contexto no es algo accesorio. Con esta intención, los autores exploran hasta las últimas consecuencias - como propone Carl Schorske - una línea de pensamiento para comprender la significación política e intelectual de una configuración de ideas. En síntesis, el libro aporta a estos dos campos en función de una apuesta más precisa: comprender la tradición de la psicología para entender las concepciones, las ideas y las intervenciones respecto a la infancia, la adolescencia y la familia $y$, con ello, enriquece un campo de enorme expansión y crecimiento en los últimos años.

En segundo lugar, el libro constituye un diálogo - nuevamente cruces - de muchos años. Sus ensayos son textos de autores que conocen a fondo la obra que están abordando - los tres artículos provienen de las tesis doctorales de los autores - y que han compartido lecturas y discusiones colectivas. Trasunta una larga inmersión, una familiaridad, incluso, íntima - como trasuntan ciertos tramos del texto de García - y cómplice - como sucede por momentos con Macchioli - con autores con quienes se ha pensado, discutido, revisado. Los tres ensayos cubren, además, períodos consecutivos aunque quedó el hiato vacío del primer peronismo - con lo cual la obra abarca una parte sustantiva del siglo XX.

El primer ensayo de Ana María Talak propone una reconstrucción de la implantación del saber psicológico - y su impacto en los niños - a partir de José Ingenieros, Victor Mercante y Rodolfo Senet. A partir de estas dos figuras, el ensayo aporta una original - y poco transitada - indagación sobre las concepciones de la naturaleza infantil conectándolas con la institución escolar. Existió, nos dice la autora, una relación clara entre una visión naturalizada que concebía lo psicológico como emanado de lo biológico pero que abría la posibilidad de que la herencia fuese influida por el medio ambiente (social). En ese marco asume especial fuerza la indagación sobre el desarrollo infantil a partir de una obsesión por identificar lo normal y lo anormal en una intervención que, como explica Talak, exige pensar el carácter político de la ciencia y su conexión con lo social. Solo así podemos comprender que la clínica y la reflexión intelectual estuvieron articuladas con el esfuerzo por ordenar, encauzar, modelar una sociedad móvil, abigarrada, conflictiva, según una visión evolucionista en la que el progreso suponía un orden familiar unívoco, un modo de vida que estigmatizaba las prácticas de los sectores populares que contravenían un orden social cuyo parangón era la civilización europea.

El segundo ensayo, escrito por Luciano García, constituye una biografía intelectual de Aníbal Ponce lo que le otorga un registro distintivo respecto a los otros dos trabajos. Pero lo hace, justamente, 
inscribiendo dicha figura en las tradiciones intelectuales y en los contextos del campo de la reflexión psicológica y científica. Ello aporta, especialmente, a la comprensión sobre las ideas de la infancia y la adolescencia en una clave escasamente explorada con anterioridad. Al hacerlo, nos permite comprender las distintas respuestas y exploraciones que Ponce fue dándose a la cuestión central de la conformación social de las funciones psíquicas (la relación entre lo natural y lo adquirido) para lo que se le impuso la indagación sobre la evolución del niño y el adolescente. En ese sentido, resulta central la identificación de un patrón de inteligibilidad que conecta al niño con el loco y el salvaje que, partiendo de Levy Bruhl y Franz Boas, le permitieron a Ponce preguntarse por las formas mentales divergentes de las civilizadas, aunque el fondo de la antinomia civilización y barbarie pervivió con una matriz eurocéntrica y una inflexión racista. Más adelante, Ponce sumó una preocupación por el problema del desarrollo infantil con Piaget y por la adolescencia con Adler lo que le abrió la reflexión sobre el descubrimiento de la ambición y la angustia en las que coloca la exploración sexual y descubrimiento de la finitud. En su última etapa despuntó su interés por la familia y la mujer en el contexto de la transición ideológica de Ponce al marxismo y de su exilio mexicano en el que el evolucionismo decantó en confianza en el progreso de la mano del proletariado y la barbarie quedó asociada con el colonialismo español.

El tercer ensayo, escrito por Florencia Macchioli, vuelve colocar en el centro un cruce, la relación de Eliseo Verón y Carlos Sluzki, referentes centrales de esos nuevos campos de estudios en los años sesenta. A partir de ellos, el artículo explora la conexión entre los desarrollos psicoanalíticos, el estructuralismo y la psicología sistémica para pensar comunicación y neurosis, una cuestión que había quedado opacada en los estudios precedentes. Ello le permite a Macchioli recuperar una preocupación por la relación entre el individuo y la sociedad a partir de la interacción entre ambos intelectuales. Ellos, críticos fuertes de la psiquiatría tradicional, realizaron desarrollos teóricos originales sobre la neurosis y propusieron una terapia de nuevo tipo centrada en lo familiar. Lo hicieron, según explica la autora, a partir del diálogo entre distintas tradiciones intelectuales (las apropiaciones europeas y norteamericanas) que despuntó en el contexto de un entramado de relaciones y vínculos (con una figura decisiva como la de Pichon Riviere y Mauricio Goldenberg) y las realidades institucionales abiertas por el surgimiento del campo de la sociología y la psicología en los años sesenta, una etapa marcada por las profundas ansiedades entorno a las mutaciones que atravesaban -o debían atravesar según los paradigmas de las nuevas disciplinas-- las relaciones familiares.

Es hora de retomar la idea de cruces para pensar no sólo el lugar desde el cual el libro fue producido sino a los propios intelectuales 
estudiados así como los fenómenos que, con ellos, iluminan los capítulos.

Un primer nexo está dado por las propias relaciones y preocupaciones de estos intelectuales. Talak estudia a Ingeniero, referente central de Ponce, que también tuvo relación con Senet y Mercante y es, también, una interacción la estudiada por Macchioli. Los ensayos, entonces, auscultan el entretejido de una red intelectual. Los autores confluyen en una preocupación mayor que supone pensar una y otra vez la relación entre lo psicológico y lo biológico, lo natural y lo social y lo "estructural" de lo psicológico en el caso de Luzki. Las lecturas supone volver a preguntarse por esta cuestión que asume, claro está, un énfasis evolucionista y naturalista más marcado en el contexto del positivismo de principios de siglo, y más de corte socio-lingüístico en los años sesenta.

Un segundo cruce involucra la indagación por la relación entre los intelectuales argentinos y Europa. En este sentido el libro propone un estudio de la recepción y las apropiaciones de tradiciones intelectuales europeas y, luego, norteamericana. Como los de Victor Mercante y Rodolfo Senet estudiados por Talak vinculados a Ponce y a éste preocupado por incorporar e incorporarse a la tradición de pensamiento europea de la que, según García, fue un difusor, un lector en su misma lengua, un divulgador que no termina de deslindarse de su herencia liberal y de otorgar plena fuerza y racionalidad a la cultura propia, latinoamericana en parte porque se consideraba, como otros intelectuales, parte de la cultura greco latina, occidental. En ese sentido, el libro aporta, especialmente, a la paradójica - y contradictoria - relación de estos intelectuales que se piensan insertos en tradiciones universales - concebidas como lo europeo o lo norteamericano - al punto de que Ponce realiza un estudio clínico de María Bashkirtseff (aristócrata ucraniana y pintora del siglo XIX) pero que no asumen con igual intensidad el estudio de lo local (por ejemplo de los adolescentes argentinos). El recorrido, en su conjunto, permite notar, no obstante, que las conexiones asumen cierto sentido diferente con Luzki quien es un traductor - un receptor - de la teoría de la comunicación y el interaccionismo norteamericano pero también que al trabajar en Estados Unidos trasporta allí la experiencia del Lanus y los aportes pichoneanos. Y lo mismo sucede con Eliseo Veron que convertido en traductor de Levy Strauss termina por instalarse en Francia pero, también, de ser el nexo de la introducción de interaccionismo, vía Luzki, en Estados Unidos.

El tercer lazo que el libro ausculta una y otra vez conecta lo intelectual, lo político y lo institucional que constituye un programa de trabajo. En este sentido, la obra aporta a los nuevos estudios históricos sobre la infancia y la familia de modo muy sustantivo. Talak, por ejemplo, exige volver sobre la institución escolar y de minorización que a comienzos de siglo, cuando se crearon oficinas y 
reparticiones escolares especialmente destinadas a evaluar a los niños (en su normalidad) y atender a los niños débiles en diálogo con las preocupaciones de Mercante y de Senet. No menos importante parecería ser colocar las ideas de Ponce más en relación con la percepción de los jóvenes y los adolescentes, concretos y reales, como peligros sociales en los años treinta. $Y$ con las inquietudes - y las intervenciones psicológicas y mediáticas - de quienes descubrían las estructuras y las enfermedades familiares y a la vez creaban y daban respuesta a las ansiedades provocadas por las contiendas en torno a los vínculos familiares en la Argentina de los años sesenta.

Atrás de estos cruces y diálogos existe un desarrollo sólido y sostenido. Se logra entrever, incluso, el diálogo entre los propios autores que han escrito un libro maduro, serio y sólido a partir de una producción individual que se nutre - y a la vez nutre - una reflexión más colectiva que nos permite entender los complejos entramados - cruces - de las tradiciones intelectuales, las intervenciones institucionales y las realidades sociales y culturales.

\section{Endereço para correspondencia Isabella Cosse \\ Universidad de Buenos Aires \\ Bulnes 169020 E c1425-DKG, Buenos Aires, BA, Argentina \\ Endereço eletrônico: isabella.cosse@gmail.com}

Recebido em: $16 / 01 / 2015$

Aceito em: 16/01/2015

\section{Notas}

* Historiadora. Su campo de estudio es la historia de las familias y las infancias en conexión con los procesos políticos, sociales y culturales. Entre sus libros se cuentan: Mafalda: historia social y política (FCE, 2014), Pareja, sexualidad y familia en los años sesenta (Siglo XXI, 2010) y Estigmas de nacimiento. Peronismo y orden familiar, 1946-1955 (FCE, 2006). Ha publicado también numerosos artículos en compilaciones y revistas académicas. 